\title{
Undernutrition and Associated Factors among Pregnant Women in Kacha Birra District, Southern Ethiopia
}

Teshome SM${ }^{1 *}$, Meskel $\mathbf{D}^{1}$, Worsa TK², Datiko $\mathbf{A}^{1}$ and Malik T ${ }^{3 *}$

${ }^{1}$ Department of Nutrition and Dietetics, Faculty of Public Health, Health Institute, J imma University, J imma, Ethiopia

${ }^{2}$ School of Public Health, College of Health Science, Arba Minch University, Arba Minch, Ethiopia

${ }^{3}$ Department of Biochemistry, College of Medicine and Health Sciences, University of Gondar, Ethiopia

*Corresponding author: Melese Sinaga Teshome, Department of Nutrition and Dietetics, Faculty of Public Health, Health Institute, J imma University, J imma, Ethiopia

Tabarak Malik, Department of Biochemistry, College of Medicine and Health Sciences, University of Gondar, Ethiopia

Received: December 09, 2020; Accepted: J anuary 12, 2021; Published: J anuary 19, 2021

\begin{abstract}
Background: Worldwide, malnutrition is a public health concern with noteworthy consequence especially in pregnant women. Maternal undernutrition may dispose mothers to poor wellbeing including infection, preeclampsia/ eclampsia, and adverse pregnancy outcomes such as preterm birth and intrauterine growth retardation. Pregnant women are exposed to nutritional deficiency because of increased metabolic needs as a result the usually end up in undernutrition. There is lack of updated information in the study area regarding nutritional status and factors among pregnant women.
\end{abstract}

Objective: To assess undernutrition and associated factors among pregnant womenin Kacha Birra district, Southern Ethiopia in 2019.

Methods: An institution-based cross-sectional study was conducted among 344 pregnant women attending antenatal care in public health facilities from February 21-March 20, 2019. A systematic sampling technique was employed. Data were collected using a structured questionnaire and analyzed by a statistical package for social science version 22 software. Both bivariate and multivariate logistic regression analyses were undergone to identify factors associated with the nutritional status of pregnant women.

Result: Among 344 pregnant women who participated in the study, $52.6 \%$ were undernourished. On the multivariable analysis; having a history of peptic ulcer disease $[(A O R=1.97$ (1.23-3.17)], husband's educational status with Illiterate to elementary $[A O R=0.589(0.369-0.940)$, medium dietary diversity score [AOR=2.931 (1.106-7.766)], high dietary diversity score [AOR=2.485 (0.915-6.747)], intestinal parasite infection [AOR=1.725 (1.086-2.742)], second trimester gestational age $[A O R=0.338(0.159-0.718)]$ had shown statistically significant association with maternal undernutrition.

Conclusion: Over half of pregnant women were in undernurition. Multisectorial collaboration and coordination among related sectors and strengthening programs targeted on adult's educational status, improved drinking water and sanitation against pregnant women's, counseling on Antenatal clinic and prevention and treatment of chronic disease during pregnancy.

Keywords: Pregnant Women; Undernutrition; Ethiopia; Antenatal Care

\section{Abbreviations}

ANC: Antenatal Care; AOR: Adjusted Odds Ratio; BMI: Body Mass Index; CI: Confidence Interval; CSA: Central Statistical Agency; DDS: Dietary Diversity Score; EDHS: Ethiopian Demographic Health Survey; LBW: Low Birth Weight; MUAC: Mid Upper Arm Circumference; PCA: Principal Component Analysis; PUD: Peptic Inflammatory Disease; SD: Standard Division; SNNPR: Southern Nation Nationalities and Peoples Region; SOP: Standard operational procedure; VIF: Variance Inflation Factor; WHO: World health organization

\section{Background}

Worldwide, malnutrition is a health concern of great significance especially in under-five children and pregnant mothers. Malnutrition is considered as a major threat to public health by the WHO [1]. In spite of comprehensive global economic growth, the prevalence of maternal undernutrition was high in Sub-Saharan Africa [2]. Ethiopia is one of the developing countries with a high load of maternal and child undernutrition. However, maternal undernutrition has declined from $30 \%$ in 2000 to $22 \%$ in 2016 but still too far from achieving the Sustainable Development Goal (SDG) [3].

Pregnancy is a perilous stage of growth and development during which maternal nutrition can powerfully affects neonatal and obstetric outcomes [4]. Best nutrition is essential to uphold the health of the mother, to have a normal and healthy delivery, and also to decrease the risk of suboptimal fetal development, birth defects and prolonged health problems in childhood [5].

Maternal undernutrition may dispose mothers to poor wellbeing including infection, preeclampsia/eclampsia, and adverse pregnancy consequences such as preterm birth and intrauterine growth retardation [6]. Pregnant mothers are mainly vulnerable to nutritional inefficiencies because of increased metabolic needs to be imposed by
Austin J Nutr Metab - Volume 8 Issue 1 - 2021

Submit your Manuscript | www.austinpublishinggroup.com

Teshome et al. (C) All rights are reserved
Citation: Teshome SM, Meskel D, Worsa TK, Datiko A and Malik T. Undernutrition and Associated Factors among Pregnant Women in Kacha Birra District, Southern Ethiopia. Austin J Nutr Metab. 2021; 8(1): 1098. 
pregnancy including developing fetus, maternal tissues and placenta linked with allied dietary risks [7].

Pregnancy rises energy requirements by thirteen perecent, protein by fifty four percent, and vitamin and mineral by zero to fifty perecent. Evidences had proven that $30,000 \mathrm{kcal}(336 \mathrm{MJ})$ is essential to growth and developments of a baby, growth placenta size and reproductive organs, yield energy for newly formed tissues and produce extra fat stores in the women $[8,9]$. The majority of recent research has revealed that from the beginning, having the right balance of key micronutrients is appropriate to ensure long term health of mothers and their infants [10].

A study in Africa showed that the burden was $23.5 \%$ in pregnant mother [11,12]. Different studies in Ethiopia reveal that the prevalence of malnutrition among pregnant women is different from place to place which ranges from $14.4 \%$ [13] to $31.8 \%$ [14]. Studies in Southern Ethiopia reveal that the prevalence of malnutrition among pregnant women is not consistent according to study done in Sidama zone, it was about $24.6 \%$ [15].

Maternal malnutrition is triggered by the complex interaction of a multitude of factors, education status, family income, marital status, severe illness, having recurrent children, household food security, socioeconomic status and greater maternal age were identified factors [16].

Studies recognized that undernourished pregnant mother were at bigger risk of having low birth weight babies [17]. The relationship between low birth weight and deprived health and nutritional status future is also well recognized, which intern causes deprived growth and development, then endup in mortality and morbidity in children [18]. Ethiopian government has developed a revised National Nutrition Prigram (NNP) in 2016 to tackel the burden of malnutrition in lactating and pregnant mother [19].

Although there were evidences in regarding maternal nutritional status but they were not updated and did not assessed an important determinantal variables [20]. The aim of this study was to assess undernutrition and associated factors at the public health facility among pregnant mother living in Kacha Birra district, southern Ethiopia.

\section{Methods}

\section{Study area and period}

This study was conducted in Kacha Birra district, southern Ethiopia. It is about $327 \mathrm{~km}$ away from Addis Ababa the capital city. Located at latitude and longitude of $7^{\circ} 12^{\prime} \mathrm{N} 37^{\circ} 46^{\prime} \mathrm{E}$ with an elevation of 1875 meters above sea level. It has 23-kebeles ( 2 urban and 21 Rural) with a total population of 127,000 populations, with 64,770 women and 62, 230, men. The district has five health inistitutions, four health centers and one hospital.

The Hospital and all health centers in the district give ANC services. The study was conducted from February - May/2019. Institution-based cross-sectional study was conducted. The source population was all pregnant womens who were attended antenatal care at all health inistitutions of Kacha Birra district and the study population was all randomly selected pregnant women who were attended antenatal care at all health inistitutions during the study period and fulfilled inclusion criteria. The inclusion criteria were, all pregnant mother who were attended ANC (antenatal care) at all health inistitutions and those who were resident at least for six months in the district and pregnant mother who were seriously ill and those who came for the $2^{\text {nd }}$ and $3^{\text {rd }}$ visit were omitted from the study.

\section{Sample size determination and sampling technique}

The sample size was calculated by using single population proportion formula using the prevalence of undernutrition among pregnant women and considering the following variables and assumptions:-

- $\quad \mathrm{CI}=95 \%$,

- $\quad$ Margin of error $=5 \%$

- $\mathrm{P}=$ Prevalence of undernutrition in pregnant women in Misso health center $30.3 \%$ [21].

- $\quad$ Non-response rate $=6 \%$

- $\quad$ Thus, a total sample size was 344 .

\section{Sampling technique and procedure}

All the five health facilities found in the district were incorporated in the study. The numbers of study subjects were allocated to each health facility according to their number of pregnants attended per year. Thus, statistically, the average number of pregnant mother who was attended ANC in each health inistitutions per year multiplied by the total sample size ( $\mathrm{n}=344)$, divided by the total number of pregnant mother attended in the entire ANC unit $(\mathrm{N}=3734)$. Lastly, the study participants were selected from each health centers using a systematic random sampling technique, the first study participant was selected by lottory method.

\section{Data collection tools and techniques}

Data were collected by face to face interviews using an interview administered questionnaire which was prepared in the English language and later translated into Amharic. The questionnaire had four parts socio-demographic, economic, dietary and reproductive parts. The standardized tool for measurement of wealth index was adopted from EDHS (Ethiopia Demographic and Health Survey)-2016.

\section{Dietary diversity by 24 -hour dietary recall}

Dietary diversity measuring questioner adopted from FANT 2006 will be employed to determine the dietary diversity status of pregnant women. A number of food-groups consumed preceding 24 hours to the survey was assessed. The foods consumed in the preceding 24-hour recall was grouped in 9 food-groups which are listed:- 1 . Grains, roots or tubers 2. Vitamin A-rich plant foods 3. other fruits or vegetable 4. Eggs, 5. Meat, poultry, 6. Fish, seafood 7. Pulses/legumes/ nuts 8 . Milk and milk products 9 .Foods cooked in oil/fat. Dietary diversity scores was made by summing up the number of food groups consumed over the previous 24 hours period by an individual and classified accordingly.

\section{Anthropometric measurements}

Maternal anthropometric measurements were done according to the standards. MUAC of a pregnant mother was measured at mid- 
point between the tip of the shoulder and the tip of the elbow of the left arm. An adult Mid-Upper Arm Circumference (MUAC) tape that was non-elastic and non-stretchable was used to take measurements, after checking that the tape was applied with correct tension. The Mid-Upper Arm Circumference (MUAC) of a pregnant mother was read and documented to the nearest $0.1 \mathrm{~cm}$. MUAC measurement was performed by clinical nurse/public health professionals following standard instructions and steps. A range below $23 \mathrm{~cm}$ was an indicator of undernutrition and a range of $>23 \mathrm{~cm}$ was for normal nutritional status

\section{Data collectors}

Data collection process was done by five qualified diploma nurses and 2 BSc health officers who are speaking the local language was participate as a data collector and supervisor respectively. One day training was given to the data collectors on the objectives and purpose of the study briefly. Simulated interviews, and real field activity was given to data collectors and supervisors to guarantee the quality of the field job.

\section{Data Processing and analysis procedures}

The data were entered with Epi-Data version 3.1 and were cleaned and analyzed by Statistical Package for the Social Sciences (SPSS) for window version 22. Descriptive statistics, mean, frequency and standard deviation were implemented. Inferential statistical tests like bivariate and multivariable logistic regression analyses were implemented. Multivariable logistic regression with backward method was used to identify associated factors of undernutrition. Before running multivariable logistic regression, multi-collinearity between independent variables was checked by Variance Inflation Factors (VIF) and no variable with VIF of $>10$ was observed. Variables that had p-value of less than 0.25 in the bivariate logistic regression models were a candidate for multivariable logistic regression. The model fitness for the variables was assessed by the Hosmer-Lemeshow goodness of fit test and produced p-value of 0 . 983. Those variables with $\mathrm{p}$-value $<0.05$ was considered as statistically significantly associated factors in the multivariable analysis. Wealth index was determined using the PCA analyses and all assumptions were checked and fulfilled [25]. Facor score were used to classify final wealth index and ranked into tertiles as "poor", "medium" and "rich".

\section{Data quality control}

A structured questionnaire was translated to Amharic and back to English for consistency, two days interactive training was given for data collectors and all standardization techniques were done. The overall data collection procedure was organized by the PI (principal investigator). The pre-test was conducted at five percent of the whole sample size in Hadaro health center, a near by health center outside the study area just one week before the data collection time. The appropriate working of instruments, laboratory reagents, and technical performance was tested by using quality control samples. SOPs and manufacturers' instructions were strictly followed beginning from sample collection up to reporting. All the laboratory processes were controlled by medical laboratory professionals.

\section{Ethics consideration}

Ethical clearance was obtained from the ethical review committee of Jimma University. Official permission was secured from the Kacha
Birra district health office. Verbal and written consent was obtained from all participants after a clear orientation of the study objective. Privacy, anonymity, and confidentiality will be ensured throughout the process of the study. Finally, those detected as undernutrition are linked to the health facility to take treatment accordingly and advice was given for them. This study was conducted in accordance with the Declaration of Helsinki

\section{Results}

\section{Demographic and socioeconomic and obstetrics characteristics}

A total of three hundred forty-four women were participated in this study with a response rate of $100 \%$. The age of the participants ranged from 15-38 years. Morethan half 180(52.2\%) participants were found in the age range of 25-29. Pertaining to maternal educational status, $66.6 \%$ were at the primary educational level. Regarding the educational status of the husband, $57.8 \%$ have completed the primary educational level. Concerning the occupational status of the participant, $63.1 \%$ were housewives. And the majority (94.7\%) of the participants were married. more than half $(63.1 \%)$ of the participants household size was 5-7 persons. Regarding residency, more than twothird $(73.3 \%)$ of respondents are living in rural areas. Regarding the birth interval, $72.4 \%$ have less than two years pregnancies interval. Concerning the gestational age of the pregnancy, more than half (52.9\%) of the participants were in the third trimester. Finally, regarding history of abortion, most of the respondents $(81.7 \%)$ had no history of abortion (Table 1).

\section{Dietary and illness-related characteristics}

Regarding maternal dietary diversity scores, more than half (55\%) of pregnant mothers were under low dietary diversity scores (Figure 1).

The majority of the respondents (93\%) have experienced consumption of tea or coffee immediately after a meal. Most of the respondents had injera with wot $71.5 \%$. Regarding the history of peptic ulcer disease, about $44.8 \%$ of respondents had developed PUD. Regarding the HIV status of the pregnant women around $14.5 \%$ were reactive for HIV. Concerning the intestinal parasite infection, more than half $57.3 \%$ of the respondents had developed intestinal parasite infection (Table 2).

Out of the total three hundred forty four pregnant mother attending the ANC in the public health facility of kacha birra district there were more than half $(52.6 \%)$ pregnant women were malnourished (Figure 2).

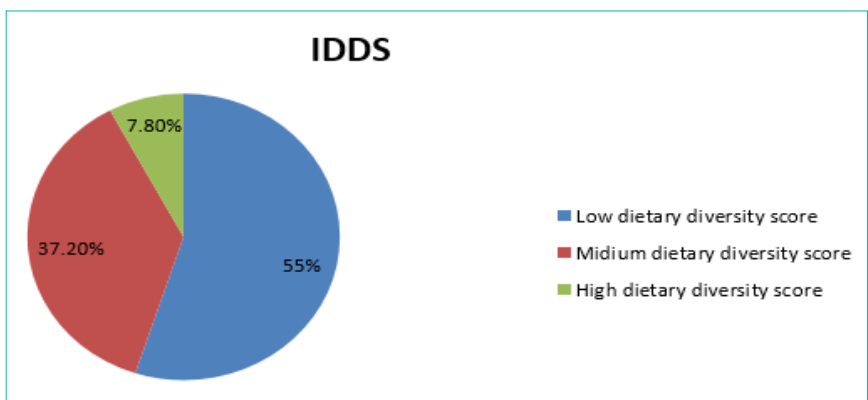

Figure 1: Dietary diversity score of pregnant mother attending ANC at public health facilities of Kacha Birra district southern Ethiopia in 2019. 
Table 1: Socio-demographic and obstetrics characteristics of the study among the pregnant mother attending ANC at public health facilities of kacha birra district southern Ethiopia in $2019(n=344)$.

\begin{tabular}{|c|c|c|c|}
\hline \multirow{2}{*}{ VARIABLES } & $\begin{array}{c}\text { MUAC } \\
\text { measurement }\end{array}$ & & \multirow[t]{2}{*}{ P-value } \\
\hline & $>23 \mathrm{~cm}$ & $<=23 \mathrm{~cm}$ & \\
\hline \multicolumn{3}{|l|}{ Residence of mother } & \multirow{3}{*}{0.118} \\
\hline Urban & $50(54.3 \%)$ & $42(45.7 \%)$ & \\
\hline Rural & $113(44.8 \%)$ & $139(55.2 \%)$ & \\
\hline Family size & $19(35.2 \%)$ & $35(64.8 \%)$ & \multirow{4}{*}{0.006} \\
\hline $1-4$ & $117(53.9 \%)$ & $100(46.1 \%)$ & \\
\hline $5-7$ & $27(37.0 \%)$ & $46(63.0 \%)$ & \\
\hline \multicolumn{3}{|l|}{$>=8$} & \\
\hline \multicolumn{3}{|l|}{ Age of mother } & \multirow{6}{*}{0.381} \\
\hline $15-19$ & $5(62.5 \%)$ & $3(37.5 \%)$ & \\
\hline $20-24$ & $35(47.9 \%)$ & $38(52.1 \%)$ & \\
\hline $25-29$ & $88(48.9 \%)$ & $92(51.1 \%)$ & \\
\hline $30-34$ & $25(37.9 \%)$ & $41(62.1 \%)$ & \\
\hline$>35$ & $10(58.8 \%)$ & $7(41.2 \%)$ & \\
\hline \multicolumn{3}{|l|}{ Marital Status } & \\
\hline Married & $149(45.7 \%)$ & $177(54.6 \%)$ & 0.013 \\
\hline Single & $12(85.7 \%)$ & $2(14.3 \%)$ & \\
\hline Other & $2(50 \%)$ & $2(50 \%)$ & \\
\hline Mother educational status & & $111(48.5 \%)$ & \multirow{3}{*}{0.03} \\
\hline Illiterate to elementary & $118(51.5 \%)$ & $70(60.9 \%)$ & \\
\hline Above elementary & $45(39.1 \%)$ & & \\
\hline Husband educational status of & $82(56.6 \%)$ & $63(43.4 \%)$ & \multirow{3}{*}{0.004} \\
\hline Illiterate to elementary & $81(40.7 \%)$ & $118(59.3 \%)$ & \\
\hline \multicolumn{3}{|l|}{ Above elementary } & \\
\hline Gestational age & $33(73.3 \%)$ & $12(26.7 \%)$ & \multirow{4}{*}{0.001} \\
\hline $1^{\text {st }}$ trimester & $51(43.6 \%)$ & $66(56.4 \%)$ & \\
\hline $2^{\text {nd }}$ trimester & $79(43.4 \%)$ & $103(56.6 \%)$ & \\
\hline \multicolumn{3}{|l|}{$3^{\text {rd }}$ trimester } & \\
\hline $\begin{array}{l}\text { Pregnancy interval b/n previous } \\
\text { and current }\end{array}$ & $91(45.0 \%)$ & $111(55.0 \%)$ & \multirow{3}{*}{0.798} \\
\hline$<=2$ yrs. & $36(46.8 \%)$ & $41(53.2 \%)$ & \\
\hline \multicolumn{3}{|l|}{$>2 y r s$} & \\
\hline \multicolumn{3}{|l|}{ History of abortion } & \multirow{3}{*}{0.102} \\
\hline Yes & $24(38.1 \%)$ & $39(61.9 \%)$ & \\
\hline No & $139(49.5 \%)$ & $142(50.5 \%)$ & \\
\hline \multicolumn{3}{|l|}{ Household wealth tertials } & \multirow{4}{*}{0.945} \\
\hline Poor & $66(48.2 \%)$ & $71(51.8 \%)$ & \\
\hline Medium & $32(45.7 \%)$ & $38(54.3 \%)$ & \\
\hline Rich & $65(47.4 \%)$ & $72(52.6 \%)$ & \\
\hline
\end{tabular}

In bivariate analysis a total of 11 variables (Residence, family size, educational status of mother, educational status of father, intestinal parasite, DDS, Gestational age, histry of chronic illness, histry of peptic ulcer disease, tea or coffee drinking and history of abortion were scred $\mathrm{p}$-value $<0.25$ and became candidate for multivariabe analysis.
Table 2: Dietary and illness-related characteristics of the study among the pregnant mother attending ANC at public health facilities of Kacha Birra district southern Ethiopia in $2019(\mathrm{n}=344)$.

\begin{tabular}{|c|c|c|c|}
\hline \multirow{2}{*}{ VARIABLES } & \multicolumn{2}{|c|}{ MUAC measurement } & \multirow{2}{*}{ P-value } \\
\hline & $>23 \mathrm{~cm}$ & $<=23 \mathrm{~cm}$ & \\
\hline \multicolumn{3}{|l|}{ Intestinal Parasite } & \multirow{3}{*}{0.011} \\
\hline No & $58(39.5 \%)$ & $89(60.5 \%)$ & \\
\hline Yes & $105(53.3 \%)$ & $92(46.7 \%)$ & \\
\hline \multicolumn{3}{|l|}{ Staple food } & \multirow{3}{*}{0.193} \\
\hline Other* & $41(41.8 \%)$ & $57(58.2 \%)$ & \\
\hline Teffe injera with wot & $122(49.6 \%)$ & $124(50.4 \%)$ & \\
\hline \multicolumn{3}{|l|}{ Malaria test result } & \multirow{3}{*}{0.282} \\
\hline Positive & $26(41.3 \%)$ & $37(58.7 \%)$ & \\
\hline Negative & $137(48.8 \%)$ & $144(51.2 \%)$ & \\
\hline \multicolumn{3}{|l|}{ Dietary diversity score } & \multirow{4}{*}{0.086} \\
\hline Low & $90(47.6 \%)$ & $99(52.4 \%)$ & \\
\hline Medium & $57(44.5 \%)$ & $71(55.5 \%)$ & \\
\hline High & $16(69.6 \%)$ & $7(30.4 \%)$ & \\
\hline \multicolumn{3}{|l|}{ History of chronic illness } & \multirow{3}{*}{0.148} \\
\hline Yes & $30(40.0 \%)$ & $45(60.0 \%)$ & \\
\hline No & $133(49.4 \%)$ & $136(50.6 \%)$ & \\
\hline History of peptic ulcer disease & $58(37.7 \%)$ & $96(62.3 \%)$ & \multirow{3}{*}{0.001} \\
\hline Yes & 105(55.3\%) & $85(44.7 \%)$ & \\
\hline \multicolumn{3}{|l|}{ No } & \\
\hline HIV status of mother & $24(48.0 \%)$ & $26(52.0 \%)$ & \multirow{3}{*}{0.925} \\
\hline Reactive & $139(47.3 \%)$ & $155(52.7 \%)$ & \\
\hline \multicolumn{3}{|l|}{ Non reactive } & \\
\hline \multicolumn{3}{|l|}{ Tea or coffee after meal } & \multirow{3}{*}{0.153} \\
\hline Yes & 155(48.4\%) & $165(51.6 \%)$ & \\
\hline No & $8(33.3 \%)$ & $16(66.7 \%)$ & \\
\hline
\end{tabular}

*(maize and sorghum, spaghetti and rice, vegetables')

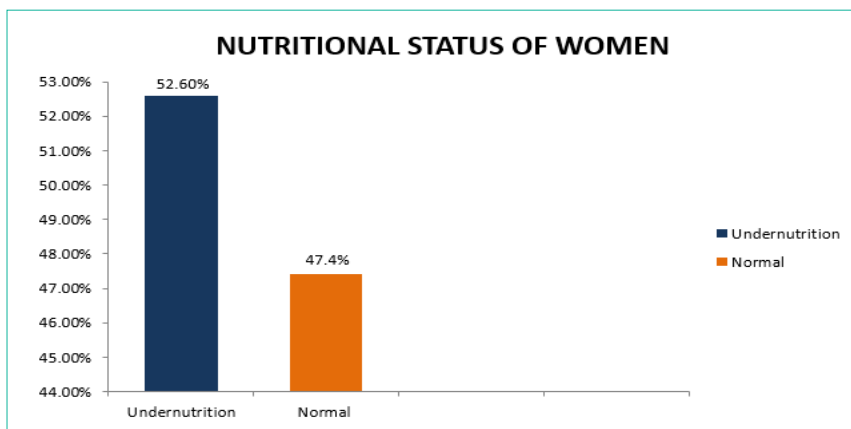

Figure 2: Nutritional status of the study among the pregnant mother attending ANC at public health facilities of kacha birra district southern Ethiopia in 2019.

Finally 6 variables (tea or coffee after the meal, gestational age, history of peptic ulcer disease, dietary diversity score, intestinal parasite, husband educational status) were secred $\mathrm{p}$-value $<0.05$ and declared as statistically significantly associated factors with undernutrition independently.

Multivariable logistic regression analysis indicated that, those 
Table 3: Multivariate logistic regression analysis among pregnant women at ANC clinic in Kacha Birra district southern Ethiopia in 2019 ( $n=344$ ).

\begin{tabular}{|c|c|c|c|c|c|c|c|}
\hline \multirow{2}{*}{ Variables } & \multicolumn{2}{|c|}{ MUAC } & \multirow{2}{*}{ COR } & \multirow{2}{*}{ AOR } & \multicolumn{2}{|c|}{ 95\% C.I. } & \multirow{2}{*}{$P$} \\
\hline & $>23 \mathrm{~cm}$ & $<=23 \mathrm{~cm}$ & & & Lower & Upper & \\
\hline Mother educational status & & & & & 0.384 & 1.169 & \\
\hline Illiterate to elementary & $118(51.5 \%)$ & $111(48.5 \%)$ & 0.605 & 0.67 & & & 0.159 \\
\hline Above elementary & $45(39.1 \%)$ & $70(60.9 \%)$ & 1 & 1 & & & \\
\hline \multicolumn{8}{|l|}{ Husband Educational status } \\
\hline \multicolumn{8}{|l|}{ Illiterate to elementary } \\
\hline \multirow[t]{2}{*}{ Above elementary } & $82(56.6 \%)$ & $63(43.4 \%)$ & 0.527 & 0.589 & 0.369 & 0.94 & \multirow{2}{*}{0.026} \\
\hline & $81(40.7 \%)$ & $118(59.3 \%)$ & 1 & 1 & & & \\
\hline \multicolumn{8}{|l|}{ Intestinal Parasite } \\
\hline No & $58(39.5 \%)$ & $89(60.5 \%)$ & 1 & 1 & 1.086 & 2.742 & 0.021 \\
\hline \multicolumn{8}{|l|}{ Dietary diversity score } \\
\hline Low & $90(47.6 \%)$ & $99(52.4 \%)$ & 2.5142 .847 & 2.931 & 1.106 & 7.766 & 0.031 \\
\hline Medium & $57(44.5 \%)$ & $71(55.5 \%)$ & 1 & 2.485 & 0.915 & 6.747 & 0.074 \\
\hline High & $16(69.6 \%)$ & $7(30.4 \%)$ & & 1 & & & \\
\hline \multicolumn{8}{|l|}{ History of peptic ulcer disease } \\
\hline Yes & $58(37.7 \%)$ & $96(62.3 \%)$ & 2.045 & 1.975 & 1.23 & 3.17 & 0.005 \\
\hline No & 105(55.3\%) & $85(44.7 \%)$ & 1 & 1 & & & \\
\hline \multicolumn{8}{|l|}{ Gestational age } \\
\hline $1^{\text {st }}$ trimester & $33(73.3 \%)$ & $12(26.7 \%)$ & 1 & 1 & & & \\
\hline $2^{\text {nd }}$ trimster & $51(43.6 \%)$ & $66(56.4 \%)$ & 0.279 & 0.338 & 0.159 & 0.718 & 0.005 \\
\hline $3^{\text {rd }}$ trimster & $79(43.4 \%)$ & $103(56.6 \%)$ & 0.993 & 0.928 & 0.594 & 1.608 & 0.928 \\
\hline No & $8(33.3 \%)$ & $16(66.7 \%)$ & 1 & 1 & & & \\
\hline
\end{tabular}

mothers of hasband with illiterate to elementary education were $41.1 \%$ [AOR $=0.589,95 \%$ CI: $0.369-0.940]$ less likely of becoming undernourished than those educational status of above elementary. The odds of becoming undernourished among pregnant women with parasitic infection on current pregnancy were 1.725 times more likely than those who did not have parasitic infection $[\mathrm{AOR}=1.725,95 \% \mathrm{CI}$ : $1.086-2.742]$

In the current study mothers gestational age had shown an association with nutritional status. The risk of undernutrition on mother's second trimester had $66.2 \%$ less likely than the First trimester.

Pregnant women who had history of peptic ulcer disease were 1.975 times more likely to develop undernutrition than those who did not had history of peptic ulcer disease $[A O R=1.975,95 \% \mathrm{CI}$ : 1.230-3.170]. Study participants with low dietary diversity score were 2.931 times more likely to became undernourished as compared to those pregnant women's who have high dietary diversity score [AOR=2.931, 95\% CI: 1.106-7.766] (Table 3).

\section{Discussion}

The overall prevalence of undernutrition in Kacha Birra District was $52.6 \%$. This finding was higher than the study conducted in
Diredawa, which was reported as $18.2 \%$ [26]. The discrepancy might be due to varation in study setting and socio economic charactersitics.

Compared to the current result, a lesser prevalence of undernutrition was revealed in Wondo Genet 9.2\% [27] which used a different cut off value with the current study; they used a Mid-Upper Arm Circumference $<21 \mathrm{~cm}$ while we were used a MidUpper Arm Circumference $<23 \mathrm{~cm}$. Likewise, studies from Hossana [15], Alamatsa [28] and Gonder [13] reported that a relatively lesser prevalence than the current study and this is might be due to the difference in socio-demographic and economic characteristics, dietary habit and difference in cutoff point of MUAC. In contrary, a study done in Aleta Chuko Southern Ethiopia revealed that the prevalence was $71.15 \%$ [29]. This might be due to difference in study period and study setting.

Those mothers whose husband's educational status from Illiterate to elementary schooled were $41 \%$ less likely to develop undernutrition compared to those mothers whose husband's educational status was above elementary schooled. It is obvious that when the more the husbands educationl status is the better the maternal nutritional status would be. This finding is lower than a study done in Alamata, Northern Ethiopia. The difference is might be due to the variation in sample size and demographic condition of the study areas [28]. 
In the current study mothers with intestinal parasite infection had shown an association with nutritional status. The odds of malnutrition among mothers who had intestinal parasite was 1.73 times higher than those without the intestinal parasite. It is evidenced that intestinal parasite is an infection so that the appetite would be decreased due to body response and there would be nutrient competition and a catabolic state.

In the current study mothers with low dietary diversity scores had shown an association with nutritional status. The odds of undernutrition on mothers who had low dietary diversity scores had 2.93 times higher than those with high dietary diversity score respectively. These is lower than a study done in Hosana Nigist Eleni hospital Southern Ethiopia, the difference is might be due to smaller in sample size and the inclusion of only one health facility in the case of study in Hosanna [15].

In the current study, mothers with a history of peptic ulcer disease had shown an association with nutritional status. The odds of undernutrition on mothers who had a history of peptic ulcer disease had 1.97 times higher than those without a history of peptic ulcer disease. It is clinically supported that any peptic ulcer had a negative effect on nutritional status because of decreased appetite and nausea and vomiting related to the PUD.

In the current study mothers, gestational age had shown an association with nutritional status. The risk of undernutrition on mother's second trimester had $66.2 \%$ less likely than the first trimester. It is fact that when the the gestational age increases similarly the gestational will increase this but in contrast there nutritional status decrease this is might be reduced food intake and decreased appetite [30].

\section{Conclusion}

There was a high prevalence of undernutrition among study participants in the current study studies. Educational status of husband, presense of intestinal parasite, low DDS, histry of peptic ulcer disease and gestatinal age of second trimester was associated with undernutrition among the pregnant mother attending ANC.

Therefore, intervention strategies addressing dietary modification, dietary diverisity, lifestyle modification and behavioral change communication factors should be enhanced especially for pregenant womens. Dual counseling service for the pregnant women's and her family during the ANC service might be also help to improve the maternal nutritional status.

\section{Acknowledgement}

First and foremost, we thank the Almighty God for giving me strength and wisdom to complete this paper. We would like to thank Jimma University institute of health, faculty of public health, department of nutrition and dietetics for giving sponsoring this study. Finally, the authors would also like to thank data collectors and study subjects for their cooperation.

\section{Funding}

The study was fully funded by Jimma University, Institute of Health, Faculty of Public Health and department of nutrition and dietetics

\section{Availability of Data and Materials}

The dataset used for this study cannot be shared and in the future interested parties may request the approval to access the data by writing to Jimma University Institutional Review Board.

\section{Authors' Contributions}

Melese Sinaga Teshome and Desalech H/Meskel conceived the research idea, conducted the data collection, data analysis, and data interpretation, wrote and reviewed the paper. Melese Sinaga Teshome, Desalech H/Meskel, Kidus Temesgen Worsa, Abrachew Datiko and Tabarak Malik reviewed and approved the final paper. MST reviewed the paper. Melese sinaga teshome; the Corresponding author had the responsibility to submit the manuscript for publication. All authors contributed toward data analysis, drafting and revising the paper and agree to be accountable for all aspects of the work.

\section{References}

1. Salunkhe AH, Pratinidhi A, Kakade SV, SalunkheJA, Mohite VR, Bhosale T Nutritional status of mother and gestational age: Online Journal of Health and Allied Sciences. 2017; 16.

2. Bain LE, Awah PK, Geraldine N, Kindong NP, Siga Y, Bernard N, et al. Malnutrition in Sub-Saharan Africa: burden, causes and prospects. Pan African Medical Journal. 2013; 15

3. Loudyi FM, Kassouati J, Kabiri M, Chahid N, Kharbach A, Aguenaou H, et al. Vitamin D status in Moroccan pregnant women and newborns: reports of 102 cases. The Pan African medical journal. 2016; 24.

4. Kramer MS. The epidemiology of adverse pregnancy outcomes: an overview. J Nutr. 2003; 133: 1592S-1596S.

5. American Dietetic Association (ADA). Position of the American Dietetic Association: nutrition and lifestyle for a healthy pregnancy outcome. Am J Diet Assoc. 2008; 108: 553-561.

6. Jiang T, Christian P, Khatry SK, Wu L, West Jr KP. Micronutrient deficiencies in early pregnancy are common, concurrent and vary by season among rural Nepali pregnant women. J Nutr. 2005; 135: 1106-1112.

7. Daba G, Beyene F, Fekadu H, Garoma W. Assessment of knowledge of pregnant mothers on maternal nutrition and associated factors in Guto Gida Woreda, East Wollega Zone, Ethiopia. J Nutr Food Sci. 2013; 3: 1.

8. Kuche D. Factors associated with dietary practices and nutritional status among pregnant women in Wondo Genet district. Ethiopian Public Health Institute. 2011.

9. Man'ombe S. Pregnant women as beneficiaries of the Vulnerable Group Feeding (VGF) programme in Mbire district Zimbabwe: An assessment of nutritional vulnerability. Master's Degree Thesis, University of the Free State. 2012.

10. Opara JA, Adebola HE, Oguzor NS, Abere SA. Malnutrition during pregnancy among child bearing mothers in Mbaitolu of south-eastern Nigeria. Adv Biol Res. 2011; 5: 111-115.

11. World Health Organization. Nutrition in the WHO African Region. Brazzaville: World Health Organization;. 2017; 3.

12. Desyibelew HD, Dadi AF. Burden and determinants of malnutrition among pregnant women in Africa: A systematic review and meta-analysis. PLoS One. 2019; 14: 1-19.

13. Dadi AF, Demelash H, Id D. Undernutrition and its associated factors among pregnant mothers in Gondar town , Northwest Ethiopia. Open Access J. 2019; 14: 1-11.

14. Mariyam AF, Dibaba B. Journal of Nutritional Disorders \& Epidemiology of Malnutrition among Pregnant Women and Associated Factors in Central Refit Valley of Ethiopia, 2016. Nutr Disord Ther. 2018; 8: 1-8.

15. Addisalem Gizahewu, Bruke B Billoro and MAY. Under Nutrition and 
Associated Factors among Pregnant Women at ANC Clinic, Nigist Elen Mohammad Memorial General Hospital, Hossana, Southern Ethiopia. Food Nutr Curr Res. 2019; 2: 158-165.

16. Black RE, Allen LH, Bhutta ZA, Caulfield LE, de Onis M, Ezzati M, Mathers $C$, et al. Maternal and child undernutrition: global and regional exposures and health consequences. Lancet. 2008; 371: 243-260.

17. Lechtig A, Yarbrough C, Delgado H, Habicht JP, Martorell R, Klein RE. Influence of maternal nutrition on birth weight. Am J Clin Nutr. 1975; 28 1223-1233.

18. Rahman MS, Howlader T, Masud MS, Rahman ML. Association of lowBirth Weight with malnutrition in children under five years in Bangladesh: do Mother's education, socio-economic status, and birth interval matter? PLoS One. 2016; 11: e0157814.

19. Federal Democratic Republic of Ethiopia. National Nutrition Program 2016 2020. 2016.

20. Kumera G, Gedle D, Alebel A, Feyera F, Eshetie S. Undernutrition and its association with socio-demographic, anemia and intestinal parasitic infection among pregnant women attending antenatal care at the University of Gondar Hospital, Northwest Ethiopia.

21. Serbesa ML, Iffa MT, Geleto M. Factors associated with malnutrition among pregnant women and lactating mothers in Miesso Health Center, Ethiopia. 2019; 0-5.

22. Mathewos Moges EL. Nutritional status and associated factors among pregnant women in Boricha Woreda, Sidama Zone, Southern Ethiopia, 2013G. C. 2013.
23. Guidelines for measuring household and individual dietary diversity.

24. Lisa Hjelm, Astrid Mathiassen, Darryl Miller AWR. Creation of a Wealth Index. 2017; 1-26.

25. Ethiopian Central Statistical Agency and ICF International. Ethiopia Demographic and Health Survey 2011. Addis Ababa, Ethiopia and Calverton, Maryland, USA: Central Statistical Agency and ICF International. 2012.

26. Shenka A, Damena M, Abdo M, Roba KT. Dietary Diversity and Nutritional Status of Pregnant Women Attending Public Hospitals in Dire Dawa City Administration, Eastern Ethiopia. 2018; 2: 10-17.

27. Desalegn Kuche, Pragya Singh, Debebe Moges, Tefera Belachew. Nutritional Status and Associated Factors among Pregnant Women in Wondo Genet District, Southern Ethiopia. J Food Sci Eng. 2015; 5: 85-94.

28. Dagne S. Undernutrition and associated factors among pregnant women attending ANC follow up in Alamata general hospital, Northern Region, Ethiopia. 2019; 9: 70-78.

29. Sonko A. Assessment of dietary practice and anthropometric status of pregnant women in Aleta Chuko Woreda Southern Nations, Nationalities and People's Region/SNNPR/, Ethiopia. J Epidemiol Public Health Rev. 2016; 1. $1-9$

30. Kedir H, Berhane $\mathrm{Y}$, Worku A. Magnitude and determinants of malnutrition among pregnant women in eastern Ethiopia: Evidence from rural, communitybased setting. Matern Child Nutr. 2016; 12: 51-63. 